\title{
Nonlinear Coefficient Determination of Au/Pd Bimetallic Nanoparticles Using Z-Scan
}

\author{
José Luis Jiménez Pérez ${ }^{1 *}$, Rubén Gutiérrez-Fuentes ${ }^{2}$, José Francisco Sánchez Ramírez, \\ Omar Uriel García Vidal ${ }^{1}$, Daniel Erick Téllez-Sánchez ${ }^{1}$, Zormy Nacary Correa Pacheco ${ }^{1}$, \\ Alfredo Cruz Orea ${ }^{3}$, Jesús Antonio Fuentes García ${ }^{1}$ \\ ${ }^{1}$ Unidad Profesional Interdisciplinaria en Ingeniería y Tecnologías Avanzadas del IPN, México, D.F., México \\ ${ }^{2}$ Centro de Investigación en Ciencia Aplicada y Tecnología Avanzada, México D.F., México \\ ${ }^{3}$ Departamento de Física, Centro de Investigación y de Estudios Avanzados del Instituto Politécnico Nacional, México, D.F., México \\ Email: ${ }^{*}$ jimenezp@fis.cinvestav.mx
}

Received March 22, 2013; revised April 22, 2013; accepted April 30, 2013

Copyright (C) 2013 José Luis Jiménez Pérez et al. This is an open access article distributed under the Creative Commons Attribution License, which permits unrestricted use, distribution, and reproduction in any medium, provided the original work is properly cited.

\begin{abstract}
In this paper we present the nonlinear optical characterization of $\mathrm{Au} / \mathrm{Pd}$ nanoparticles in order to obtain the nonlinear refractive indices using the Z-scan technique. The experiments were performed using a $514 \mathrm{~nm}$ laser beam $\mathrm{Ar}^{+}$, with 14 $\mathrm{Hz}$ of modulation frequency, as excitation source. By using a lens the excitation beam was focused to a small spot and the sample was moved across the focal region along the z-axis by a motorized translation stage. Seven samples with different concentration ratio of $\mathrm{Au} / \mathrm{Pd}$ nanoparticles were prepared by simultaneous reduction of gold and palladium ions in presence of poly ( $N$-vinyl-2-pirrolidone) (PVP) using ethanol as a reducing agent. In this work, we report the application of the Z-scan technique, to generate optical transmission of laser light as a function of the $\mathrm{z}$ position for solutions containing bimetallic nanoparticles of $\mathrm{Au}$ (core)/Pd (shell) with average sizes ranging from 3 to $5 \mathrm{~nm}$. The magnitude of the obtained nonlinear refractive index was in the order of $10^{-8} \mathrm{~cm}^{2} / \mathrm{W}$. Our results show that the nonlinear refractive index has a nonlinear behavior when the $(\mathrm{Au} / \mathrm{Pd})$ ratio was increased.
\end{abstract}

Keywords: Nanofluids; Nanoparticles; Nonlinear Refractive Indices; Z-Scan

\section{Introduction}

Bimetallic nanoparticles (NPs) have attracted great interest among the scientific and technological community since they lead to many interesting size dependent electrical, chemical, and optical properties [1-3]. Specifically they often exhibit enhanced catalytic properties which differ from that of their monometallic counterparts, in thin films [4]. On the other hand, the studies for new nonlinear optical materials have increasing interest in the past years, due to the numerous applications in various fields such as optical communication devices and electronics [5]. Nanoparticles colloids in solution have been studied extensively because of their large third-order nonlinear susceptibilities and nonlinear optical response $[6,7]$, chemical and biological sensors [8,9], optical energy transport $[10,11]$, nonlinear thermal material $[12,13]$, thermal therapy $[14,15]$ and medicine [16].

$\mathrm{Z}$-scan technique is one of the simplest and effective tools for measuring third order of nonlinear optics such

${ }^{*}$ Corresponding author. as nonlinear refraction coefficient and absorption. It has been widely used in material characterization $[17,18]$. This method utilizes a focused laser beam that is intense enough to access nonlinearities in a sample. As the sample passes through the focal point of the beam, changes in its transmittance, due to nonlinear absorption and nonlinear refraction, can be measured by using an open aperture and close aperture experimental setup, respectively. In the open aperture technique the beam is focused into a detector, after passed through the sample. As the sample travels through the focus of the initial beam, the transmittance either increase or decrease (depending on the nonlinearity of the sample) and the detector receives more or less light than the linear transmittance, yielding a hump or dip in the curve of transmittance as a function of the sample position. For nonlinear refraction, after the beam passes through the sample, it is attenuated by a semiclosed aperture that usually allows less than $50 \%$ of the initial beam to be detected by the detector. The converging and diverging of the beam (allowing more and less of the beam to pass through the aperture, respectively) due 
to the changes in the refractive index, a pre-focal valley and post-focal peak are observed for a positive change in refractive index. While a pre-focal peak and a post-focal valley is observed for a negative change in refraction index.

In this paper we studied the effect of the concentration of $\mathrm{Au} / \mathrm{Pd}$ ratio on their nonlinear refraction coefficient. Therefore, we report this effect using a single beam Zscan technique. The results of this method are found to be in good agreement with the values of other works.

\section{Methods}

\subsection{Sample Preparation}

Colloidal dispersion of $\mathrm{Au} / \mathrm{Pd}$ bimetallic nanoparticles was prepared by simultaneous reduction of gold and palladium ions in presence of poly ( $N$-vinyl-2-pirrolidone) (PVP) using ethanol as a reducing agent [19-22]. In a typical synthesis process, ethanol solutions of palladium chloride $(0.033 \mathrm{mmol}$ in $25 \mathrm{ml}$ of ethanol) were prepared in advance by stirring dispersions of $\mathrm{PdCl}_{2}$ powder in ethanol for $48 \mathrm{hrs}$. Solutions of tetrachloroauric acid $(0.033 \mathrm{mmol}$ in $25 \mathrm{ml}$ of water) were prepared by dissolving the $\mathrm{HAuCl}_{4} \cdot 3 \mathrm{H}_{2} \mathrm{O}$ crystals in water. For preparing bimetallic nanoparticles, solutions containing two metal ions were mixed in $50 \mathrm{ml}$ of pure ethanol/water $(1 / 1 \mathrm{v} / \mathrm{v}) .151 \mathrm{mg}$ of PVP (Aldrich, average molecular weight 10,000$)$ was added to the total metal ion content of $6.66 \times 10^{-5} \mathrm{~mol}$. The mixture solution was stirred and refluxed at about $100^{\circ} \mathrm{C}$ for $1 \mathrm{hr}$. For the preparation of bimetallic nanoparticles with different $\mathrm{Au} / \mathrm{Pd}$ ratios (10/1, $5 / 1,2 / 1,1 / 1,1 / 2,1 / 5$ and $1 / 10)$, metal ion solutions of corresponding molar ratios were mixed and refluxed at $100^{\circ} \mathrm{C}$ for $1 \mathrm{hr}$ under agitation. The ethanol/water volumetric ratio of $1: 1$ and total ion content of $6.6 \times 10^{-5} \mathrm{~mol}$ was maintained in the final $50 \mathrm{ml}$ solution. The same procedure was followed to prepare the monometallic palladium $(\mathrm{Pd})$ particles. For the preparation of monometallic gold $(\mathrm{Au})$ particles, $23.5 \mathrm{ml}$ of PVP solution (75.5 $\mathrm{g}$ in $23.5 \mathrm{ml}$ of water) was added to the gold ion solution, and then an aqueous solution of $\mathrm{NaBH}_{4}(0.066$ $\mathrm{mmol}$ in $1.5 \mathrm{ml}$ of water) was added to the resulting solution at $25^{\circ} \mathrm{C}$. The colloidal dispersions thus prepared are stable, with 3 - $5 \mathrm{~nm}$ in average diameter and narrow size distributions. In order to obtain the aqueous nanofluids containing $\mathrm{Au} / \mathrm{Pd}$ bimetallic nanoparticles, the colloidal dispersions were subsequently dried in vacuum and the metallic particles were dissolved in water maintaining the same initial concentrations of metal content and were placed in a quartz cuvette of $1 \mathrm{~mm}$ thick for the optical and thermal optical measurements. All the experiments were performed at room temperature.

\subsection{Z-Scan Technique}

Among the techniques used to characterize the complex susceptibility, the most popular is the Z-scan method. Since its introduction in 1989 [23], this technique has gained importance due to its simplicity compared to other techniques used to measure the nonlinear refraction and absorption of optical materials. In addition to the simplicity of the experimental setup, a Z-scan measurement provides a sensitive method for the determination of the signal on values of the real and imaginary parts of $x$. The technique relies on the basic idea of relating the beam center intensity variation to the refractive index variation. This can be done by monitoring the normalized transmittance as a function of the sample path along the incident beam, for a positive nonlinearity. In the case of a negative nonlinearity, the curve is inverted.

The transmittance variation between peak and valley positions is proportional to the induced phase shift, $\Delta \Phi_{o}$ and therefore to the nonlinear refractive index $\left(\mathrm{n}_{2}\right)$ is calculated using the standard relations by means of the following equations $[24,25]$ :

$$
\begin{gathered}
T(z, \Delta \Phi)=1+4 \Delta \Phi_{0}\left(z / z_{0}\right) /\left(\left(z / z_{0}\right)^{2}+1\right)\left(\left(z / z_{0}\right)^{2}+9\right) \\
\Delta \Phi_{0}=k \mathrm{n}_{2} \mathrm{I}_{0} \text { Leff }
\end{gathered}
$$

where $z$ is the position, $z_{0}$ is the Rayleigh length, $\Delta \Phi_{0}$ is the phase change due to the nonlinear refraction, $\mathrm{n}_{2}$ is the nonlinear refractive index, $k=2 \pi / \lambda$ is the wave vector, $\mathrm{I}_{0}$ $=1.8 \times 10^{3} \mathrm{~W} / \mathrm{cm}^{2}$ is the on-axis irradiance at focus (i.e., $z=0)$, and Leff $=\left[1-\exp \left(-\alpha_{0} \mathrm{~L}\right) / \alpha_{0}\right]$ is the effective length of nonlinear medium, $\alpha_{0}$ is the linear absorption coefficient of the samples ( $\mathrm{L}$ denotes the sample thickness). The nonlinear refractive index, $\mathrm{n}_{2}$ was calculated from $\Delta T_{p-v}$ being this parameter the value of peak to valley of data transmittance from the closed aperture $\mathrm{Z}$ scan measurement which can be described as [24]:

$$
\Delta T_{p-v}=0.406(1-S)^{0.25}\left|\Delta \Phi_{0}\right|
$$

Here $S$ is the linear transmittance of the aperture. Figure 1 shows the schematic diagram of a single beam $Z$ scan experimental setup used in the present measurement. The experiments were performed using a $\mathrm{CW} \mathrm{Ar}^{+}$laser beam, $514 \mathrm{~nm}$ wavelength (model Cyonics, Uniphase). The beam was focused to a small spot using a lens and

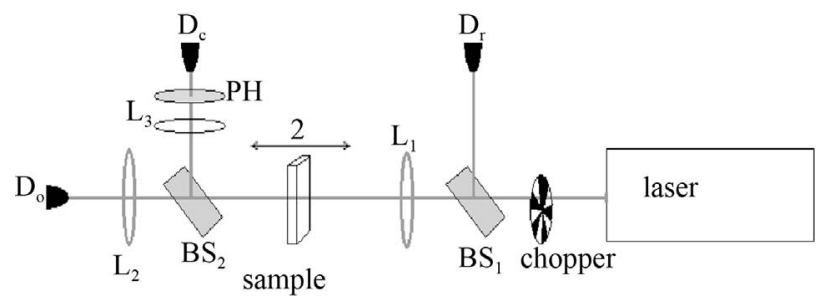

Figure 1. Experimental setup for the nonlinear laser spectroscopy. The closed and open aperture signals are proportional to the real and imaginary parts of $n_{2}$, respectively. 
the sample was scanned along a Z-axis by a motorized translation stage (Zaber). The transmitted light, in the far field, passed through the closed and open apertures and was recorded by the detectors $D_{c}, D_{o}$ and $D_{r}$ (reference detector). The laser beam waist $\omega_{0}$ at the focus length was measured to be $10.9 \mu \mathrm{m}$ and the Rayleigh length was found to be satisfied the basic criteria of the Z-scan experiment.

A quartz optical cell, $1 \mathrm{~mm}$ thick, containing the specimen solution was translated across the focal region along the z-axial direction. All the measurements were carried out at room temperature for both closed aperture and open aperture configurations.

Optical absorption spectra of the fluid samples were measured using a UV-Vis-NIR double beam spectrophotometer (Shimadzu UV3101PC).

For transmission electron microscopic (TEM) observations, a drop of fluids was spread on a carbon coated copper microgrid. A JEOL JEM200 microscope was used for the low magnification of the samples.

\section{Results and Discussion}

The absorption spectra of the $\mathrm{Au} / \mathrm{Pd}$ nanofluids at different ratios $(10 / 1,5 / 1,2 / 1,1 / 1,1 / 2,1 / 5,1 / 10)$ were measured by spectrophotometer. The measurements of absorption spectra were carried out at room temperature for visible wavelength, $350-800 \mathrm{~nm}$. The spectra are shown in Figure 2.

Figure 3 displays a typical TEM images showing the particles with a uniform distribution and uniform shape. The average particle size obtained from TEM images was $3.9 \mathrm{~nm}$.

For closed aperture setup normalized transmittance is attributed to the nonlinearity of the refractive index which was considered here [26]. In Figures 4-10 the closed aperture $\mathrm{Z}$-scan curves obtained for $\mathrm{Au} / \mathrm{Pd}$ nanofluid, at different concentration, at beam intensity of $I_{0}=1.8 \times$

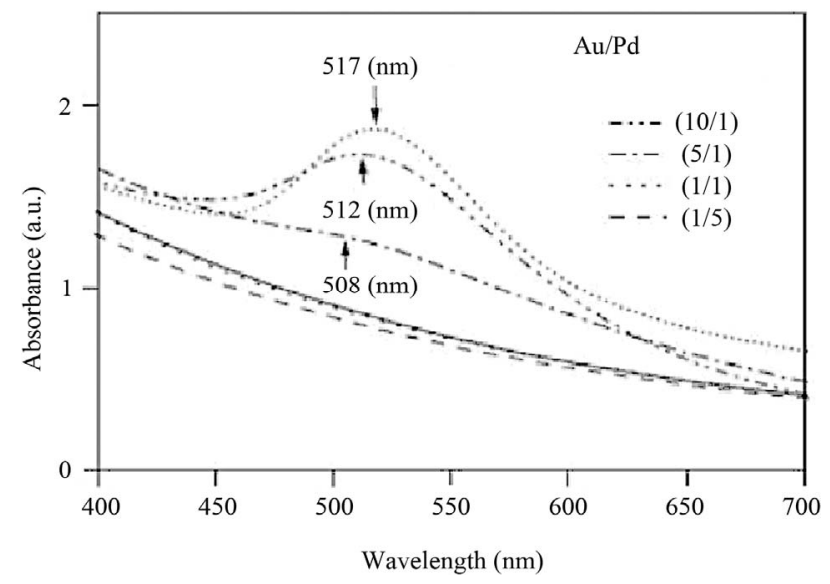

Figure 2. Optical absorption spectra of bimetallic nanoparticles with different $\mathrm{Au} / \mathrm{Pd}$ mole ratios.
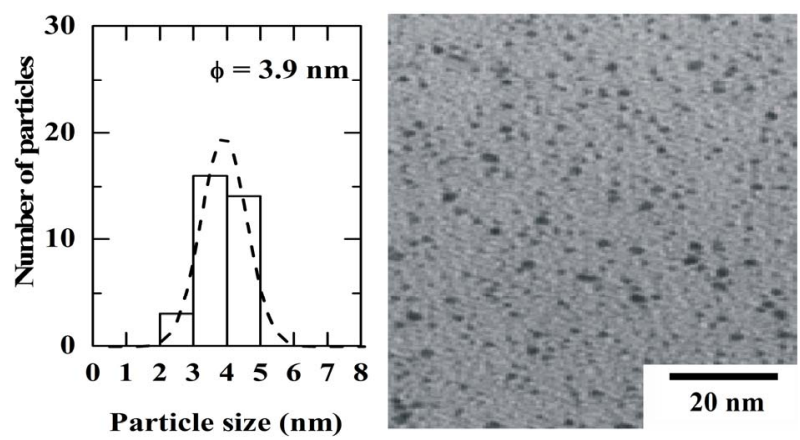

Figure 3. TEM image of $\mathrm{Au} / \mathrm{Pd}$ particles with an average size of $3.9 \mathrm{~nm}$.

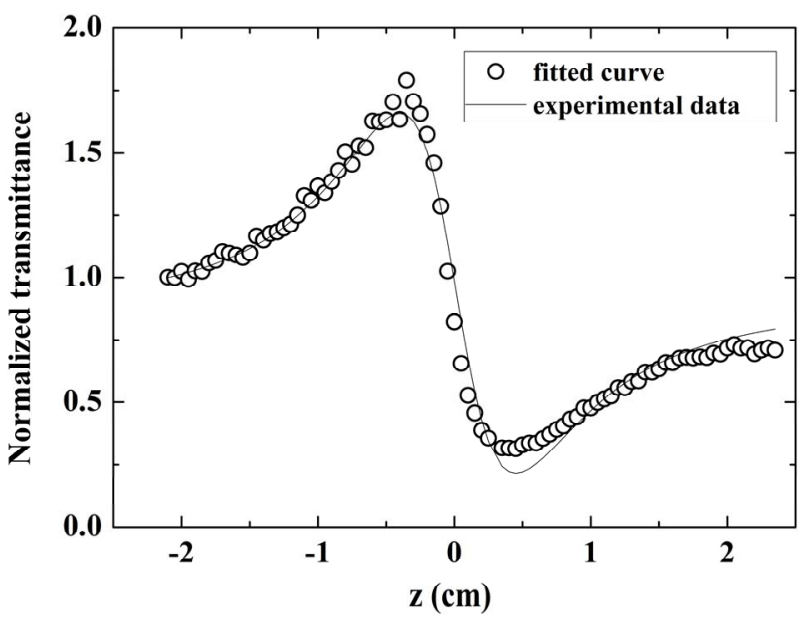

Figure 4. Closed aperture Z-scan curve for $\mathrm{Au} / \mathrm{Pd}$ nanoparticles at a concentration 10/1. The solid line is the best fitting of the standard closed aperture equations to the experimental data.

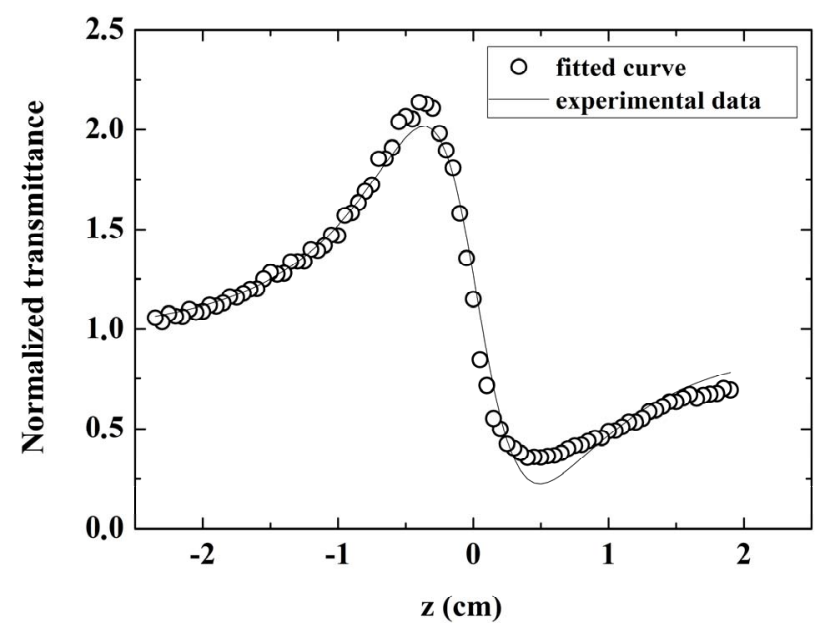

Figure 5. Closed aperture Z-scan curve for Au/Pd nanoparticles at a concentration $5 / 1$. The solid line is the best fitting of the standard closed aperture equations to the experimental data.

$10^{3} \mathrm{~W} / \mathrm{cm}^{2}$ are shown. The circle symbols represent the experimental data while the solid lines are theoretical fits 


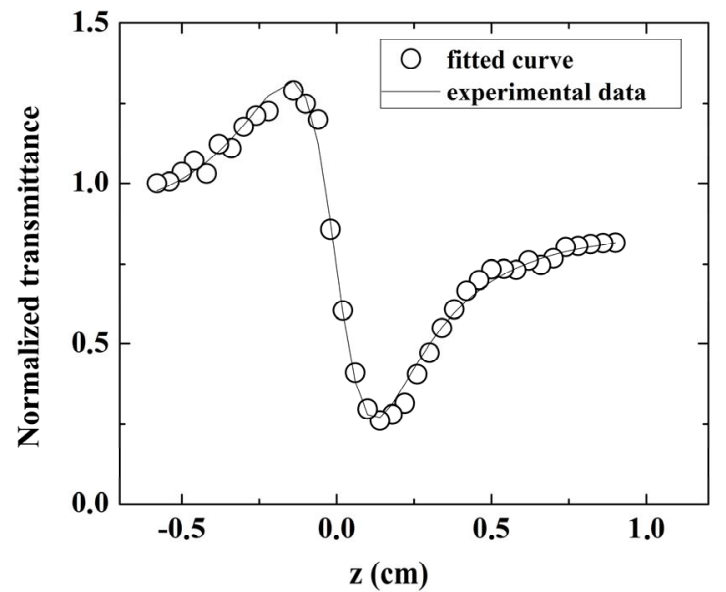

Figure 6. Closed aperture Z-scan curve for Au/Pd nanoparticles at a concentration $2 / 1$. The solid line is the best fitting of the standard closed aperture equations to the experimental data.

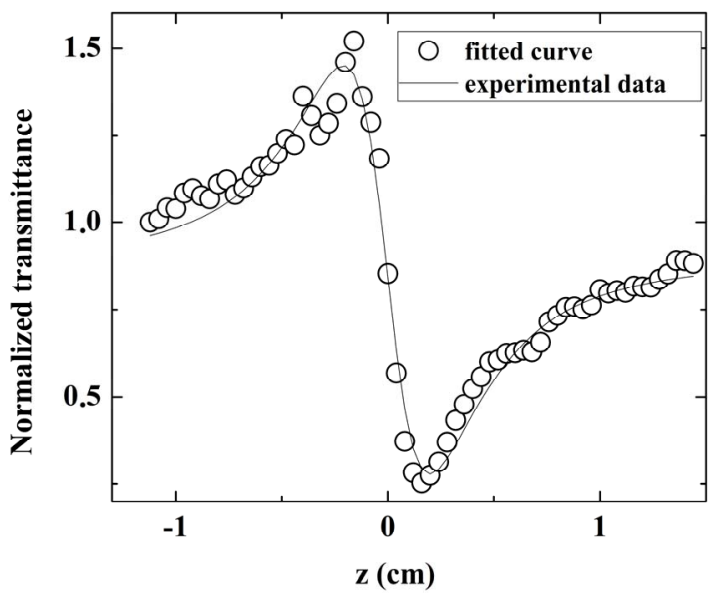

Figure 7. Closed aperture Z-scan curve for $\mathrm{Au} / \mathrm{Pd}$ nanoparticles at a concentration 1/1. The solid line is the best fitting of the standard closed aperture equations to the experimental data.

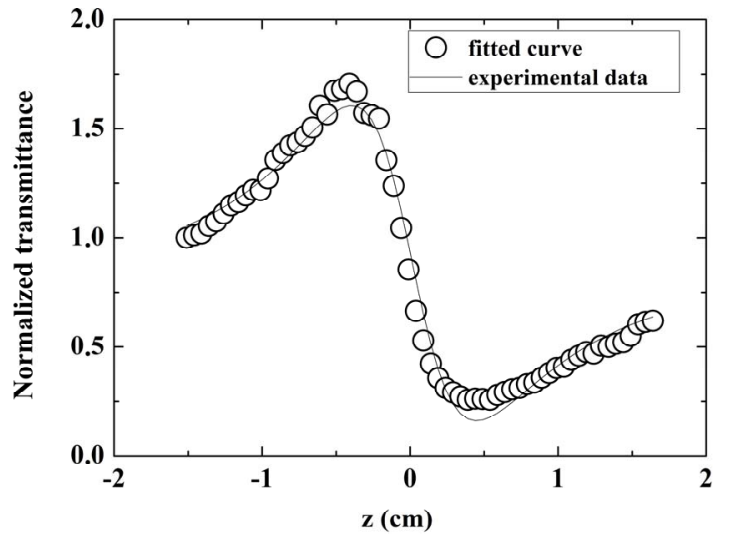

Figure 8. Closed aperture Z-scan curve for $\mathrm{Au} / \mathrm{Pd}$ nanoparticles at a concentration $1 / 2$. The solid line is the best fitting of the standard closed aperture equations to the experimental data.

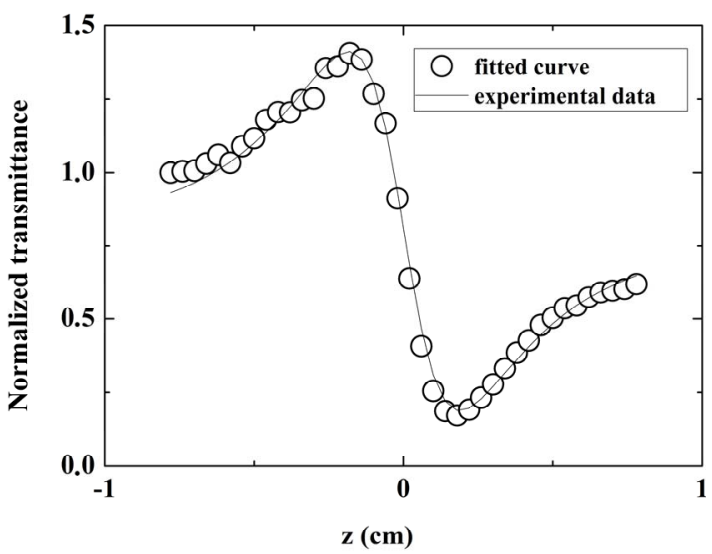

Figure 9. Closed aperture Z-scan curve for $\mathrm{Au} / \mathrm{Pd}$ nanoparticles at a concentration $1 / 5$. The solid line is the best fitting of the standard closed aperture equations to the experimental data.

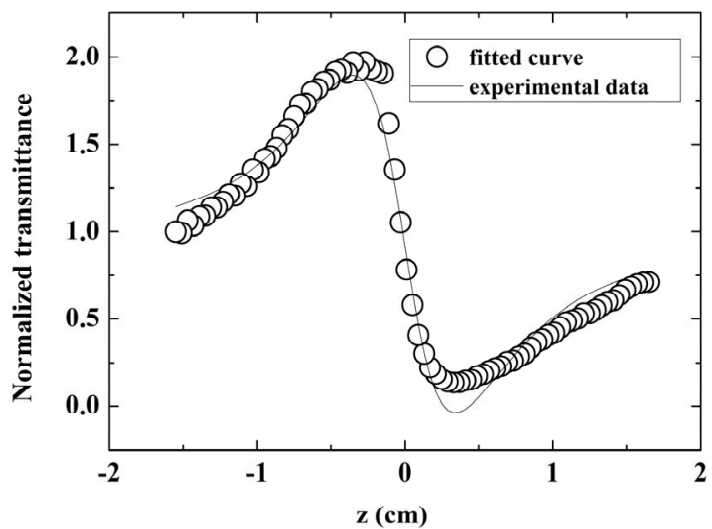

Figure 10. Closed aperture Z-scan curve for $\mathrm{Au} / \mathrm{Pd}$ nanoparticles at a concentration $1 / 10$. The solid line is the best fitting of the standard closed aperture equations to the experimental data.

to the closed aperture.

The theoretical transmittance curves presented in Figures 4-10 are fitted very well with the experimental data and they show symmetry curves. The peak follow by valley illustrate a self-focusing effect for a negative change in refraction. The solid line shows the theoretical fitting using a well-known normalized transmittance.

The nonlinear refraction coefficients $\mathrm{n}_{2}\left(\mathrm{~cm}^{2} / \mathrm{W}\right)$ together with the values of linear absorption of all samples obtained in the present work are listed on Table 1.

Figure 11 shows the variation of the nonlinear refraction index coefficient as a function of concentrations for different ratios. The nonlinear refraction coefficient decrease with increasing of concentration $(\mathrm{Au} / \mathrm{Pd}(10 / 1)$ to $\mathrm{Au} / \mathrm{Pd}(2 / 1))$. By other hand, if the concentration is inverse $(\mathrm{Au} / \mathrm{Pd}(1 / 1)$ to $\mathrm{Au} / \mathrm{Pd}(1 / 10))$, the nonlinear refraction coefficient increases with the increasing of concentration. However the increase of nonlinear of refractive index coefficient with the concentration did not show a 
Table 1. Nonlinear optical properties of $\mathrm{Au} / \mathrm{Pd}$ nanofluid at different concentrations. Molar ratios of $10 / 1,5 / 1,2 / 1,1 / 1$, $1 / 2,1 / 5,1 / 10$ were measured at $514 \mathrm{~nm}$ laser beam.

\begin{tabular}{ccccc}
\hline $\mathrm{Au} / \mathrm{Pd}$ & $\Delta T_{p v}$ & $\Delta \varphi_{0}$ & $\alpha\left(\mathrm{cm}^{-1}\right)$ & $\mathrm{n}_{2}\left(\mathrm{~cm}^{2} / \mathrm{W}\right)$ \\
\hline $10 / 1$ & 1.48 & 3.99 & 13.5 & $-13.0 \times 10^{-8}$ \\
$5 / 1$ & 1.78 & 5.21 & 10 & $-8.59 \times 10^{-8}$ \\
$2 / 1$ & 1.03 & 3.02 & 7.9 & $-3.93 \times 10^{-8}$ \\
$1 / 1$ & 1.27 & 3.72 & 6.9 & $-4.23 \times 10^{-8}$ \\
$1 / 2$ & 1.45 & 4.25 & 8.9 & $-6.23 \times 10^{-8}$ \\
$1 / 5$ & 1.24 & 3.63 & 6.28 & $-3.76 \times 10^{-8}$ \\
$1 / 10$ & 1.84 & 5.39 & 6.84 & $-6.08 \times 10^{-8}$ \\
\hline
\end{tabular}

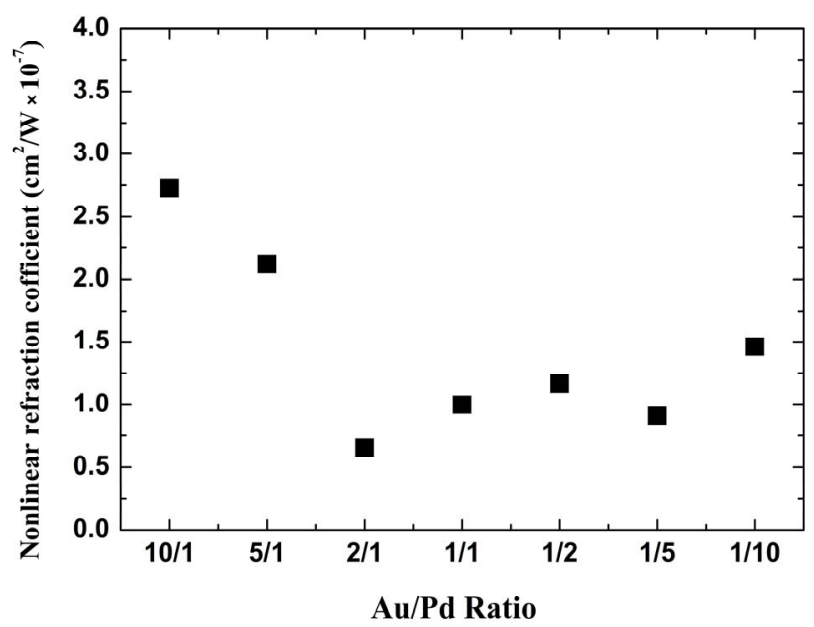

Figure 11. Variation of the nonlinear refraction index coefficient as a function of $\mathrm{Au} / \mathrm{Pd}$ ratio.

linear relationship as displayed in Figure 11. Shahriari et al. [26] studied the effect of concentration and particle size on nonlinearity of Au nanofluid prepared by $\gamma\left({ }^{60} \mathrm{Co}\right)$ radiation. From the experimental results [26], the authors obtained values of refractive index coefficient nonlinear of the same order found in this work.

\section{Conclusion}

The nonlinearity properties of $\mathrm{Au} / \mathrm{Pd}$ nanofluid prepared at different concentrations have been successfully investigated using a single beam Z-scan method. A CW, $\mathrm{Ar}^{+}$ laser beam, at wavelength $514 \mathrm{~nm}$, was used as excitation source. The $\mathrm{Au} / \mathrm{Pd}$ nanofluid shows a good nonlinear response. The sign of the nonlinear refractive index is found to be negative and the magnitude is in the order of $10^{-8} \mathrm{~cm}^{2} / \mathrm{W}$. A nonlinear relationship was obtained for nonlinear refractive index as a function of $\mathrm{Au} / \mathrm{Pd}$ ratio. Until our knowledge these results are reported for the first time in the literature. These results showed that $\mathrm{Au} / \mathrm{Pd}$ nanofluid has significant values of nonlinear refractive index, thus it could be good candidate for nonlinear thermal material.

\section{Acknowledgements}

The authors are thankful to the Mexican Agencies, CONACYT, CGPI-IPN and COFAA-IPN for financial supports.

\section{REFERENCES}

[1] H. Kumarakuru, D. Cherns, M. G. Montes de Oca and D. J. Fermin, "TEM Studies of Stress Relaxation in Catalytic Au-Pd Core-Shell Nanoparticles," Journal of Physics: Conference Series, Vol. 371, 2012, Article ID: 012025.

[2] C. Hsu, C. Huang, Y. Hao and F. Liu, "Au/Pd Core-Shell Nanoparticles for Enhanced Electrocatalytic Activity and Durability," Electrochemistry Communication, Vol. 23, No. 1, 2012, pp. 133-136. doi:10.1016/j.elecom.2012.07.027

[3] M. A. Montero, M. R. Gennero de Chialvo and A. C. Chialvo, "Electrocatalytic Activity of Core-Shell Au@Pt Nanoparticles for the Hydrogen Oxidation Reaction," International Journal of Hydrogen Energy, Vol. 36, No. 6, 2011, pp. 3811-3816.

[4] F. Liu, D. Wechsler and P. Zhang, "Alloy-Structure-Dependent Electronic Behavior and Surface Properties of Au-Pd Nanoparticles," Chemical Physics Letters, Vol. 461, No. 4-6, 2008, pp. 254-259. doi:10.1016/j.cplett.2008.07.029

[5] Y. Dirix, C. Bastiaansen, W. Caseri and P. Smith, "Oriented Pearl-Necklace Arrays of Metallic Nanoparticles in Polymers: A New Route toward Polarization-Dependent Color Filters," Advanced Materials, Vol. 11, No. 3, 1999, pp. 223-227.

doi:10.1002/(SICI)1521-4095(199903)11:3<223::AID-A DMA223>3.0.CO;2-J

[6] L. L. Beecroft and C. K. Ober, "Nanocomposite Materials for Optical Applications," Chemical Materials, Vol. 9, No. 6, 1997, pp. 1302-1317. doi:10.1021/cm960441a

[7] Y. Wang, "Nonlinear Optical Properties of NanometerSized Semiconductor Clusters," Accounts of Chemical Research, Vol. 24, No. 5, 1991, pp. 133-139. doi:10.1021/ar00005a002

[8] R. Elghanian, J. J. Storhoff, R. C. Mucic, R. L. Letsinger and C. A. Mirkin, "Selective Colorimetric Detection of Polynucleotides Based on the Distance-Dependent Optical Properties of Gold Nanoparticles," Sciences, Vol. 227, No. 5329,1997, pp. 1078-1081. doi:10.1126/science. 277.5329 .1078

[9] C. Loo, A. Lin, L. Hirsch, M. Lee, J. Barton, N. Halas, J. West and R. Drezek, "Nanoshell-Enabled Photonics-Based Imaging and Therapy of Cancer," Technology in Cancer Research and Treatment, Vol. 3, No. 1, 2004, pp. 33-40.

[10] M. Quinten, A. Leitner, J. R. Krenn and F. R. Aussenegg, "Electromagnetic Energy Transport via Linear Chains of Silver Nanoparticles," Optics Letters, Vol. 23. No. 17, 1998, pp. 1331-1333. doi:10.1364/OL.23.001331

[11] M. L. Brongersma, J. W. Hartman and H. A. Atwater; "Electromagnetic Energy Transfer and Switching in Nanoparticle Chain Arrays below the Diffraction Limit," Physical Review B, Vol. 62, No. 24, 2000, pp. R16356- 


\section{R16359. doi:10.1103/PhysRevB.62.R16356}

[12] H. Nadjari and Z. A. Azad, "Determining the Nonlinear Coefficient of Gold and Silver Nano-Colloids Using SPM and CW Z-Scan," Optics and Laser Technology, Vol. 44, No. 5, 2012, pp. 1629-1632. doi:10.1016/j.optlastec.2011.11.013

[13] W. Husinsky, A. Ajami, P. Nekvindova, B. Svecova, J. Pesicka and M. Janecek, "Z-Scan Study of Nonlinear Absorption of Gold Nano-Particles Prepared by Ion Implantation in Various Types of Silicate Glasses," Optics Communications, Vol. 285, No. 10, 2012, pp. 2729-2733. doi:10.1016/j.optcom.2012.01.044

[14] L. R. Hirsch, R. J. Stafford, J. A. Bankson, S. R. Sershen, R. E. Price, J. D. Hazle, N. J. Halas and J. L. West, "Nanoshell-Mediated Near-Infrared Thermal Therapy of Tumors under Magnetic Resonance Guidance," Proceedings of the National Academy of Sciences of the United States of America, Vol. 100, No. 23, 2003, pp. 13549-13554. doi:10.1073/pnas.2232479100

[15] E. Shahriari, W. M. M. Yunus and E. Saion, "Effect of Particle Size on Nonlinear Refractive Index of Au Nanoparticle in PVA Solution," Brazilian Journal of Physics, Vol. 40, No. 2, 2010, pp. 256-260. doi:10.1590/S0103-97332010000200021

[16] A. N. Dhinaa and K. Palanisamy, "Optical Nonlinearity in Measurement of Urea and Uric Acid in Blood," Natural Science, Vol. 2, No. 2, 2010, pp. 106-111. doi:10.4236/ns.2010.22017

[17] S. Guo, L. Xu, H. Wang, X. You and N. Ming, "Determination of Optical Nonlinearities in $\mathrm{Cu}$ (mpo) 2 by ZScan Technique," Optical and Quantum Electronics, Vol. 35, No. 7, 2003, pp. 693-703. doi:10.1023/A:1023981924486

[18] E. Shahriari, W. Mahmood Mat Yunus, K. Naghavi and Z. A. Talib, "Investigating of Nonlinear Refractive index Ag Nano-Fluid Based on Variation Particles Size," Journal of Basic and Applied Sciences, Vol. 1, No. 3, 2009, pp. 455-458.

[19] N. Toshima, M. Harada, Y. Yamazaki and K. Asakura, "Catalytic Activity and Structural Analysis of PolymerProtected Gold-Palladium Bimetallic Clusters Prepared by the Simultaneous Reduction of Hydrogen Tetrachloroaurate and Palladium Dichloride," Journal of Physical Chemistry, Vol. 96, No. 24, 1992, pp. 9927-9933. doi:10.1021/j100203a064

[20] Y. Wang and N. Toshima, "Preparation of Pd-Pt Bimetallic Colloids with Controllable Core/Shell Structures," Journal of Physical Chemistry B, Vol. 101, No. 27, 1997, pp. 5301-5306. doi:10.1021/jp9704224

[21] M. Harada, K. Asakura and N. Toshima, "Catalytic Activity and Structural Analysis of Polymer-Protected Gold/Palladium Bimetallic Clusters Prepared by the Successive Reduction of Hydrogen Tetrachloroaurate(III) and Palladium Dichloride," Journal of Physical Chemistry, Vol. 97, No. 19,1993, pp. 5103-5114. doi: $10.1021 / \mathrm{j} 100121 \mathrm{a} 042$

[22] J. F. Sánchez-Ramírez, J. L. Jiménez Pérez, A. Cruz Orea, R. Gutiérrez Fuentes, A. Bautista-Hernández and U. Pal, "Thermal Diffusivity of Nanofluids Containing Au/Pd Bimetallic Nanoparticles of Different Compositions," Journal of Nanoscience and Nanotechnology, Vol. 6, No. 3, 2006, pp. 1-6. doi:10.1166/jnn.2006.124

[23] M. Sheik-Bahae, A. A. Said and E. W. Van Stryland, "High-Sensitivity, Single-Beam $\mathrm{n}_{2}$ Measurements," $O p$ tics Letters, Vol. 14, No. 17, 1989, pp. 955-957. doi:10.1364/OL.14.000955

[24] M. Sheik Bahae, A. A. Said, T. Huei Wei, D. J. Hagan and E. W. Van Stryland, "Sensitive Measurement of Optical Nonlinearities Using a Single Beam," IEEE Journal of Quantum Electronics, Vol. 26, No. 4, 1990, pp. 760769. doi:10.1109/3.53394

[25] E. Shabriari and W. M. M. Yunus, "Single Beam Z-Scan Measurements of Nonlinear Refraction and Nonlinear Absorption Coefficients in Silver Nano-Fluid," American Journal of Applied Sciences, Vol. 3, No. 1, 2010, pp. 98101. doi:10.3844/ajeassp.2010.98.101

[26] E. Shahriari, W. Mahmood Mat Yunus, K. Naghavi and Z. A. Talib, "Effect of Concentration and Particle Size on Nonlinearity of Au Nano-Fluid Prepared by $\gamma\left({ }^{60} \mathrm{Co}\right) \mathrm{Ra}-$ diation," Optics Communications, Vol. 283, No. 9, 2010, pp. 1929-1932. doi:10.1016/j.optcom.2010.01.005 